\title{
Pengaplikasian Teori Precede Proceed dalam Upaya Pemberdayaan Masyarakat di Kelurahan Sidotopo
}

\section{Application of the Precede Proceed Theory for Community Empowerment in Sidotopo Village}

Amalia Ayu Mandasari* ${ }^{1}$, Ira Nurmala ${ }^{1}$

\begin{abstract}
ABSTRAK
Latar Belakang: Sebuah pemberdayaan masyarakat berguna untuk memampukan dan memandirikan masyarakat. Dimana begitu banyak permasalahan masyarakat yang ada, salah satunya permasalahan kesehatan, seperti lingkungan yang tercemar oleh sampah. Permasalahan akibat sampah dapat berdampak pada $25 \%$ ikan yang mengandung plastik, $80 \%$ sampah yang berada di laut merupakan sampah dari darat, merusak lingkungan sekitar, menyebabkan penyakit seperti disentri dan DBD serta dapat juga menurunkan derajat kesehatan masyarakat yang bermukim di wilayah tersebut. Salah satu wilayah yang mengalami permasalahan sampah adalah Kelurahan Sidotopo, tepatnya di wilayah RW XI, Kota Surabaya.

Tujuan: Untuk membantu masyarakat RW XI agar dapat meningkatkan kesadaran tentang kesehatan lingkungan serta memampukan masyarakat untuk menanggulangi permasalahan yang ada pada lingkungannya.

Metode: Proses pemberdayaan masyarakat RW XI Kelurahan Sidotopo Kota Surabaya dengan sasaran penelitian masyarakat yang memiliki balita dan dilakukan pada tanggal 26 Desember 2019 hingga 31 Januari2020. Metode yang digunakan yaitu dengan metode deskriptif kualitatif dengan design cross sectional dan untukmelakukan implementasi menggunakan kerangka teori precede proceed.

Hasil: Hasil penelitian berupa masyarakat dapat terbantu untuk meningkatkan kesadaran tentang kesehatan lingkungan serta memampukan masyarakat untuk menanggulangi permasalahan yang ada pada lingkungannya.

Kesimpulan: Pembentukan kebijakan oleh masyarakat sekitar dan pembentukan laskar sebagai pelopor kesehatan masyarakat di wilayah RW XI Kelurahan Sidotopo Kota Surabaya.
\end{abstract}

Kata kunci: pemberdayaan masyarakat, permasalahan kesehatan, sampah

\begin{abstract}
Background: Community empowerment helps enable an independent society. There are so many community problems that exist, one of which is health problems, such as an environment polluted by garbage. The pain due to waste can have an impact on $25 \%$ of fish containing plastic, $80 \%$ of waste in the sea is garbage from land, damages the surrounding environment, causes diseases such as dysentery and dengue and can also reduce the health status of the people who live in the area. One of the areas experiencing waste problems is Sidotopo Village, to be precise in the RWXI area, Surabaya City.

Objectives: To help $R W$ XI's community increase awareness about environmental health and enable the communityto overcome problems in their environment.

Method: The community empowerment process of RW XI Kelurahan Sidotopo, Surabaya City, with the target of community research with toddlers and carried out from December 26, 2019, to January 31, 2020. The method used is a qualitative descriptive method with a cross-sectional design to carry out implementation using the precede proceedings theoretical framework.

Results: The research results in the form of the community can help to increase awareness about environmental health and enable the community to overcome problems in their environment.

Conclusion: to increase awareness about environmental health and enable the community to overcome problems in their environment.
\end{abstract}

Keywords: community empowerment, health problem, trash 


\author{
*Koresponden: \\ amalia.ayu.mandasari- \\ 2018@fkm.unair.ac.idAmalia Ayu \\ Mandasari \\ ${ }^{1}$ Departemen Promosi Kesehatan dan Ilmu Perilaku, Fakultas Kesehatan Masyarakat, Universitas \\ AirlanggaKampus C Mulyorejo, 60115, Surabaya, Jawa Timur, Indonesia
}

\title{
PENDAHULUAN
}

Pemberdayaan masyarakat merupakan sebuah upaya yang memiliki harkat dan martabat untuk meningkatkan golongan masyarakat dalam kondisi kekurangan atau miskin, sehingga mereka dapat melepas diri dari kondisi keterbelakangan dan kemiskinan (Andayani, Martono and Muhamad, 2017) . Pemberdayaan masyarakat adalah segala upaya fasilitasi yang sifatnya non-instruktif, yang berguna untuk meningkatkan pengetahuan dan kemampuan masyarakat agar mampu mengidentifikasi masalah yang dihadapi, potensi yang dimiliki, merencanakan, dan melakukan pemecahannya dengan memanfaatkan potensi setempat (Peraturan Menteri Kesehatan No.65, 2013). Dengan kata lain, pemberdayaan pada masyarakat berguna untuk memampukan dan memandirikan masyarakat. Salah satu permasalahan pada masyarakat adalah tentang masalah kesehatan. Dalam suatu pemberdayaan, ada beberapa kajian seperti Enabling, Empowering dan Protecting yang mana semua intinya adalah agar membuat masyarakat dapat mengambil keputusan sendiri sesuai dengan keadaan lingkungan mereka (Margolang, 2018).

Menurut H.L. Bloom ada beberapa masalah kompleks yang dapat mempengaruhi yakni terdiri dari faktor lingkungan (fisik, sosial, budaya, dan politik), faktor genetik, faktor sarana dan prasarana pelayanan kesehatan serta faktor perilaku perorangan dan masyarakat (Mawaddah, 2019). Begitu banyaknya faktor yang mempengaruhi masalah kesehatan sehingga dapat menurunkan derajat kesehatan masyarakat juga berhubungan dengan kurangnya kesadaran masyarakat, seperti adanya pencemaran lingkungan seperti sampah. Sampah merupakan salah satu masalah kesehatan masyarakat yang masih cukup banyak dihadapi oleh masyarakat Indonesia. Hampir semua masyarakat di Indonesia memiliki kebiasaan untuk membuang sampah sembarangan baik masyarakat yang masih rendah maupun menengah ke atas (Wibisono and Dewi, 2014). Perbedaan tingkat pendidikan yang dimiliki oleh masyarakat tidak menjadikan masyarakat tersebut memiliki perbedaan sikap dan perilaku terhadap masalah sampah (Mulasari, 2013). Oleh karena itu, permasalahan tersebut sangat membutuhkan kerjasama antar masyarakat untuk saling menjaga kebersihan lingkungan agar derajat kesehatan masyarakat dapat meningkat (Elamin et al., 2018). Dukungan antar masyarakat yang terbentuk, nantinya juga akan membentuk perilaku masy arakat dalam menanggulangi permasalahan terkait sampah hingga mengolah sampah (Febriandi, 2020).

Berdasarkan data dari Kementrian Lingkungan Hidup dan Kehutanan, 80\% sampah yang berada di laut berasal dari daratan yang dikarenakan kurangnya lahan untuk pengolahan limbah padat dan sampah yang terbawa dari aliran sungai. Hasil penelitian dari Universitas Hasanuddin dan University of California, Davis School of Veterinary Medicine, menemukan sekitar 25\% ikan yang dijual di pasar Kota Makassar telah mengandung plastik (Kementrian Lingkungan hidup dan Kehutanan, 2017). Pencemaran sampah sendiri dapat mengganggu biota laut dan pengelolaan sampah yang kurang baik juga dapat mengganggudan merusak lingkungan sekitar. Lingkungan yang tercemar dapat membahayakan kesehatan dan menimbulkan penyakit seperti disentri dan diare pada masyarakat yang tinggal diwilayah tersebut(Widiyanto, Yuniarno and Kuswanto, 2015). Selain penyakit disentri dan diare, penyakit Demam Berdarah Dengue (DBD) merupakan salah satu dampak dari penyumbatan sampah di saluran pembuangan yang mengakibatkan berkembangannya jentik nyamuk (Dahlan, Kapas and Yogyakarta, 2018).

Pada wilayah Kelurahan Sidotopo Kecamatan Semampir, Kota Surabaya, berdasarkan profil kesehatan Puskesmas Sidotopo tahun 2019 dan hasil primer didapatkan 7 (tujuh) masalah kesehatan di Kelurahan Sidotopo, salah satunya adalah permasalahan tentang pengolahan sampah. Kelurahan Sidotopo sendiri merupakan salah satu bagian dari Kecamatan Semampir di wilayah Kota Surabaya, Jawa Timur. Kelurahan Sidotopo memiliki kepadatan penduduk sebanyak $11.870 \mathrm{Jiwa} / \mathrm{Km}^{2}$ dengan luas wilayah 2.98 $\mathrm{Km}^{2}, 12$ Rukun Warga (RW) dan 96 Rukun Tetangga (RT). Kelurahan Sidotopo merupakan wilayah kerja dari Puskesmas Sidotopo, jumlah penduduk laki-laki di kelurahan Sidotopo adalah 17.756 Jiwa sedangkan jumlah penduduk perempuan 17.616 Jiwa dengan jumlah Kepala Keluarga (KK) sebesar 9.949 KK (Badan Pusat Statistik, 2019).

Permasalahan sampah yang dialami oleh wilayah Sidotopo tersebut dikarenakan oleh beberapa faktor, seperti wilayah yang berada di sekitar aliran sungai, tidak terdapatnya tempat pengumpulan atau pengolahan sampah di wilayah tersebut serta terkendalanya proses pengangkutan sampah masyarakat. Hal tersebut menyebabkan masyarakat memilih untuk langsung membuang sampah di aliran sungai atau dibiarkan menumpuk di depan rumah yang mana dapat menganggu kesehatan masyarakat sekitar. Adapun faktor penghambat lainnya yakni kepadatan dan penyebaran penduduk pada wilayah tersebut serta ekonomi 
masyakarat sekitar (Sahil et al., 2016). Selain itu, tidak terdapat kebijakan atau aturan pada suatu wilayah akan semakin mendukung kondisi lingkungan yang tidak sehat (Indartik et al., 2018).

Wilayah Sidotopo adalah salah satu wilayah dengan permasalahan sampah yang cukup rumit. Wilayah tersebut berada di perlintasan kereta api dan berbatasan dengan sungai. Sampah yang dibuang sembarangan oleh masyarakat, baik dari RW XI maupun RW lainnya terkadang juga ikut terbawa oleh kereta api yang lewat di perlintasan. Hal tersebut semakin membuat keadaan lingkungan menjadi lebih kotor dan tidak indah untuk dipandang. Sampah yang berterbangan tidak hanya sampah plastik tapi terkadang juga sampah popok bayi. Sampah plastik yang berterbangan mempunyai dampak negatif seperti dapat mengurangi tingkat kesuburan dari tanah, dapat menyumbat saluran drainase, selokan, dan aliran sungai yang membuat daerah tersebut banjir ketika musim penghujan (Purwaningrum, 2016). Tujuan dari pembentukan program tersebut adalah untuk membantu masyarakat sekitar agar dapat meningkatkan kesadaran tentang kesehatan lingkungan serta memampukan masyarakat untuk menanggulangi permasalahan yang ada pada lingkungannya. Dalam artikel ini,akan disampaikan perencanaan dan proses implementasi yang dilakukan dalam kegiatan ini melalui pendekatan Precede Proceed.

\section{METODE}

Penelitian yang digunakan adalah metode penelitian deskriptif kualitatif dengan design penelitian cross sectional. Metode penelitian deskriptif dilakukan dengan menggunakan survei. Pendekatan tersebut berguna untuk mempelajari hubungan antara faktor-faktor berisiko dengan efek, melalui observasi atau pengumpulan data sekaligus pada suatu waktu tertentu. Penelitian dilakukan dengan mencari informasi berupa data mengenai kondisi wilayah yang memiliki permasalahan dengan sampah.

Berdasarkan hasil data yang didapatkan, salah satu wilayah di daerah Sidotopo yang dipilih sebagai tempat untuk implementasi program pemberdayaan masyarakat terkait permasalahan kesehatan (sampah) yakni di wilayah RW XI Kelurahan Sidotopo, Kecamatan Semampir, Kota Surabaya, dengan cakupan wilayah kerja RT 01-10. Sasaran yang diteliti memiliki kriteria yaitu masyarakat yang memiliki balita. Waktu penelitian ini adalah 26 Desember 2019 sampai dengan 31 Januari 2020. Dalam implementasi program pemberdayaan masyarakat tersebut akan menggunakan teori kerangka kerja precede proceed.

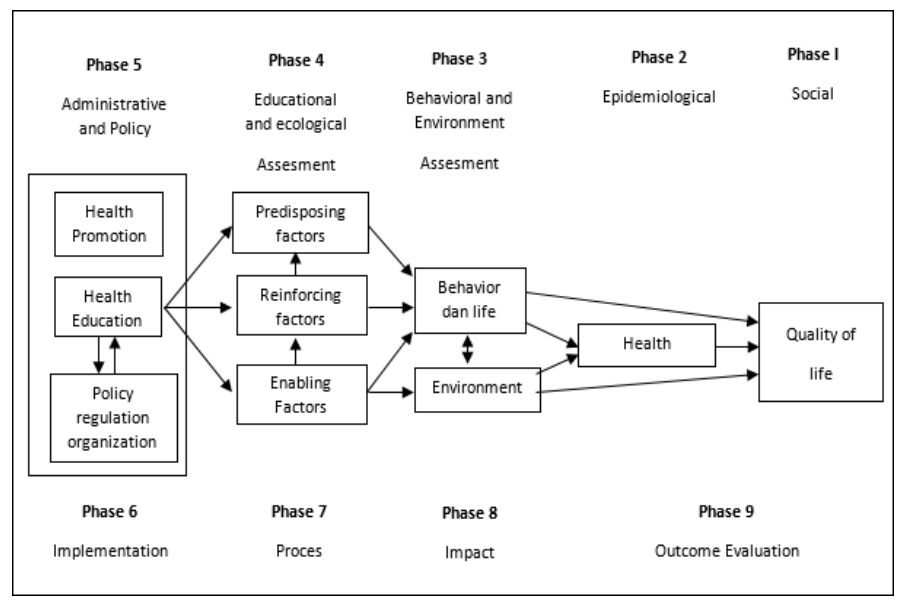

Gambar 1. Skema teori PRECEDE-PROCEED (Green and Kreuter, 1999)

\section{HASIL DAN PEMBAHASAN}

Berdasarkan proses identifikasi masalah yang telah dilakukan terhadap subjek pemberdayaan dengan model PRECEDE yang terdiri dari 5 fase, yaitu diagnosis sosial, diagnosis epidemiologi, diagnosis perilaku dan lingkungan, diagnosis pendidikan dan organisasi, dan diagnosis administrasi dan kebijakan.

\section{Social}

Pada diagnosis sosial, kualitas hidup masyarakat di Kelurahan Sidotopo khususnya RW XI tergolong masih rendah. Berdasarkan data statistik, jumlah masyarakat yang belum bekerja sebanyak 9.044, mengurus rumah tangga 7.737, dan pedagang 56 orang (Badan Pusat Statistik, 2019). Hal tersebut diperkuat dengan indepth interview yang dilakukan serta hasil kuesioner. Berdasarkan kuesioner dan indepth interview yang sudah dilakukan didapatkan hasil bahwa banyak masyarakat yang tidak mendapatkan jaminan sosial, pelayanan kesehatan yang tidak memadai (Jaminan Kesehatan Nasional). 
Lalu kepala keluarga yang memiliki pencaharian sebagai pegawai serabutan dan pendidikan yang rendah. Selain itu, masyarakat RW XI memiliki rumah yang jauh dari kondisi sehat, seperti kurangnya cahaya yang masuk dalam rumah, lalat yang berterbangan di sekitar area tempat tinggal, hingga sampah yang berserakan tanpa memiliki tutup. Berdasarkan penelitian sebelumnya pada penilaian sosial, masyarakat mengatakan bahwa seseorang akan memiliki kehidupan yang berkualitas apabila kesehatannya terjamin, pendidikan dan status ekonomi yang dimiliki (Sulaeman, Murti and Kunci, 2015). Masyarakat di wilayah RW XI dapat dikatakan bahwa mereka memiliki kualitas hidup yang kurang. Namun, masyarakat di wilayah RW XI tidak terganggu dengan hal tersebutdan sudah terbiasa dengan kondisi lingkungannya.

\section{Epidemiological}

Pada Diagnosis epidemiologi, data primer yang didapatkan dari hasil observasi lapangan pada wilayahRW XI Kelurahan Sidotopo, terdapat 7 permasalahan yang memiliki persentase paling tinggi.

Tabel 1. Persentase permasalahan di RW XI Kelurahan Sidotopo.

\begin{tabular}{|c|c|c|}
\hline NO. & Permasalahan & Persentase / Jumlah \\
\hline 1. & Sampah Berserakan & $63,01 \%$ \\
\hline 2. & Baduta Batuk Pilek & $56,20 \%$ \\
\hline 3. & Perilaku BABS (Buang Air Besar Sembarangan) & $55,72 \%$ \\
\hline 4. & Imunisasi tidak lengkap & $43,84 \%$ \\
\hline 5. & $\begin{array}{l}\text { Baduta (Anak dibawah Dua Tahun) mengalami } \\
\text { stunting }\end{array}$ & 9 anak \\
\hline 6. & $\begin{array}{l}\text { Baduta (Anak dibawah Dua Tahun) tidak } \\
\text { mendapatkan vitamin A }\end{array}$ & $32,88 \%$ \\
\hline 7. & Masyarakat meludah sembarangan & $34,25 \%$ \\
\hline
\end{tabular}

Dari hasil persentase tersebut dilanjutkan dengan penentuan prioritas masalah atau sering disebut dengan metode USG (Urgency, Seriousness, Growth). Metode USG merupakan cara untuk melihat seberapa mendesak suatu masalah, tingkat keseriusan untuk segera menangani masalah dengan memahami konsekuensi yang muncul apabila masalah tersebut tidak segera diselesaikan (Ariyanti et al., 2020). Dimana hal tersebut merupakan proses untuk diagnosis perilaku dan lingkungan pada wilayah RW XI Kelurahan Sidotopo yang dilakukan dengan FGD (Focus Group Discussion).

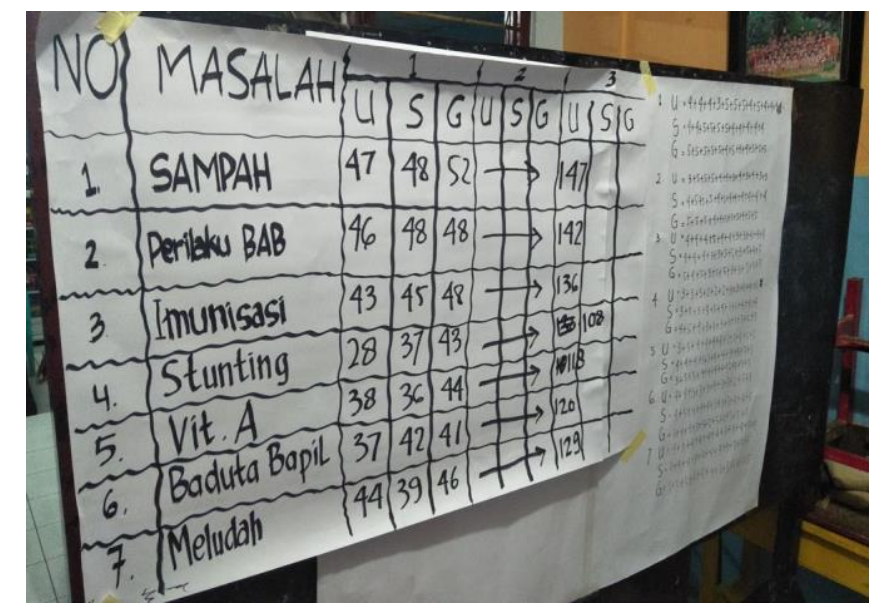

Gambar 2. Penentuan prioritas masalah dengan USG (Urgency, Seriousness, Growth)

\section{Behavioral and Environment Assesment}

Pada proses FGD yang dilakukan bersama 8 warga perwakilan dari RW XI dapat disimpulkan bahwa perilaku masyarakat RW XI memiliki kebiasaan untuk buang sampah di sembarang tempat seperti aliran sungai. Dikatakan pula bahwa perilaku masyarakat tersebut dirasa lebih cepat dan efisien karena lokasi rumah yang dekat dengan sungai. Selain itu, didapatkan hasil juga bahwa ada sebagian warga yang tertib untuk tidak buang sampah di sungai, namun belum memiliki sampah yang layak seperti tempat sampah yang tidak tertutup. 
Setelah proses FGD, dilanjutkan dengan melakukan indepth interview pada stake holder seperti RT/RW. Hal tersebut dilakukan untuk mengetahui kebijakan atau program yang telah dilaksanakan oleh para petinggi dalam mengatasi masalah di lingkungannya. Berdasarkan indepth interview yang dilakukan, mendapatkan hasil bahwa hanya beberapa RT yang melakukan pengangkutan sampah, sehingga hal tersebut menyebabkan masyarakat masih saja membuang sampah sembarangan. Pengangkutan sampah yang dilakukan juga tidak langsung diletakkan pada TPS (Tempat Penampungan Sementara) melainkan pada lahan kosong yang berada di RW XI. Jadwal pengangkutan yang tidak rutin juga membuat masyarakat melakukan alternatif lain dengan cara membuang di sungai maupun lahan kosong.

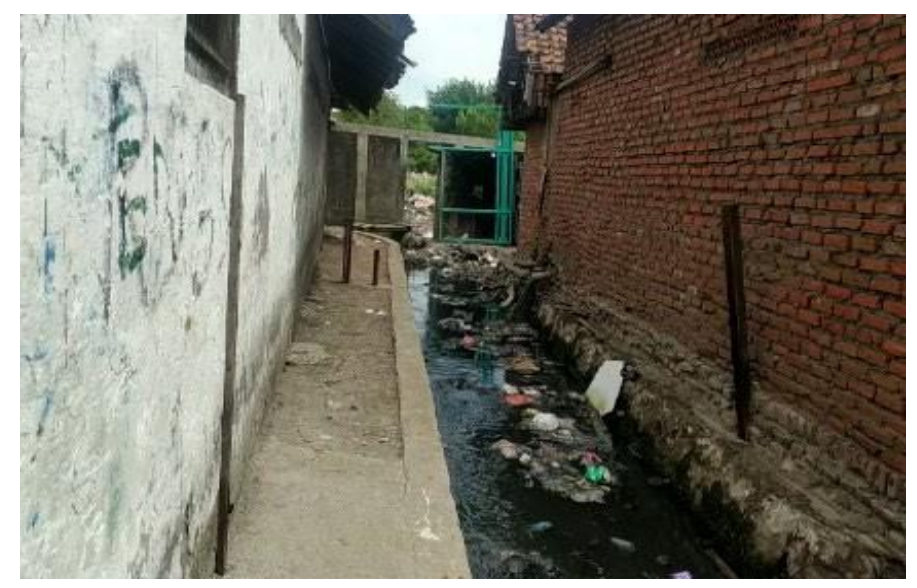

Gambar 3. Kondisi sampah yang terbawa dari aliran sungai di lingkungan RW XI

Jadwal pengangkutan sampah di RW XI yang berbeda menjadi salah satu hal yang memungkinkan masyarakat untuk membuang sampah sembarangan, terutama di sungai. Seperti pada RT 1 yang memiliki jadwal pengangkutan sampah sendiri dan hanya pada RT tersebut. Sedangkan pada 5 RT lainnya mempunyai petugas pengangkutan sampah yang sama dan jadwal pengangkutan yang bersamaan.

\section{Educational and Ecological}

Faktor-faktor yang dapat digunakan pada fase 4 dalam precede untuk diagnosis pendidikan dan organisasi, yakni predisposing factor, enabling factor, dan reinforcing factor. Hasil yang didapatkan pada predisposing factor yakni bahwa masyarakat RW XI tidak merasa terganggu melihat sampah berserakan. Hal tersebut karena masyarakat RW XI berpikir bahwa sampah tidak menjadi masalah serta tidak mengetahui tentang akibat yang ditimbulkan dari membuang sampah sembarangan. Adanya permasalahan terkait sampah juga didukung dengan tempat tinggal masyarakat yang dekat dengan sungai sehingga masyarakat merasa lebih mudah untuk membuang sampah di sungai. Selain itu, letak penampungan sampah yang terlalu jauh dari pemukiman, jadwal pengangkutan sampah yang tidak rutin serta tempat sampah yang dimiliki juga tidak memadai sehingga, mendukung masalah di lingkungan tersebut..

\section{Administrative and Policy}

Permasalahan sampah pada masyarakat RW XI yang dapat dikatakan jauh dari kata sehat tersebut mengakibatkan sebuah kebiasaan masyarakat untuk melakukan buang sampah sembarang di sungai, antar tetangga tidak ada yang saling tegur ketika ada yang membuang sampah sembarangan di sungai. Berbeda dengan penelitian yang telah dilakukan sebelumnya, masyarakat daerah RW XII Kelurahan Banguntapan, Bantul lebih memilih sampah dihancurkan dengan dibakar atau hanya dibuang sembarangan saja (Tentama, 2017).

Lingkungan RW XI Kelurahan Sidotopo juga tidak memiliki sanksi yang mengikat bagi warga yang membuang sampah sembarangan. Himbauan yang ada hanyalah kebijakan untuk membayar sukarela untuk pengangkutan sampah. Selain itu, adanya keterbatasan dalam penyediaan gerobak sampah serta kurangnya tenaga untuk pengangkutan sampah juga menjadi penghambat sistem pengelolaan sampah.

\section{Implementation}

Berdasarkan hasil diagnosis yang telah didapatkan melalui metode Precede, disusunlah program yang dinamakan "Program Sapu Jagad". Kata "Sapu” melambangkan kebersihan sedangkan "Jagat" melambangkan semesta sehingga Program sapu jagad memliki makna kebersihan secara menyeluruh. Dalam program ini diharapkan dapat menjadi usaha untuk membentuk masyarakat sadar terhadap permasalahan sampah serta masyarakat juga dapat mengolah sampah dengan baik. Langkah awal program 
ini adalah mengajak koordinasi dan melakukan proses advokasi bersama dengan masyarakat RW XI Kelurahan Sidotopo. Kesepakatan dan kebijakan terkait permasalahan sampah, seperti pengadaan gerobak sampah dan petugas, kesepakatan terkait pengelolaan sampah dan sanksi untuk masyarakat yang membuang sampah di sungai. Lalu dilanjutkan dengan pembentukan laskar sapu jagat, yang mana pesertanya adalah karang taruna RW XI dan para kader.

Dalam pembentukan laskar tersebut, para karang taruna diberi materi tentang pengelolaan sampah 3R (Reduce Reuse Recycle) dan dilatih untuk pembuatan kompos takakura. Pengelolaan sampah juga telah dilakukan oleh penelitian sebelumnya, yakni dengan pembentukan bank sampah (Maya, Haryono and Kholisya, 2018). Selain pelatihan untuk membuat kompos takakura, dilakukan juga penandatanganan komitmen bersama oleh karang taruna RW XI, kader dan ketua RT 1 -10 untuk selalu menjaga kebersihan lingkungan dan melanjutkan program sapu jagat. Tujuan penandatanganan tersebut agar masyarakat sekitar saling mengingatkan satu dengan yang lain untuk bergotong royong demi kesehatan dan kebersihan bersama.

\section{Impact}

Adanya Laskar Sapu Jagat tersebut kepada masyarakat RW XI yang membuang sampah sembarangan serta dapat mengedukasi masyarakat sekitar tentang permasalahan sampah dan cara pengolahan sampah yang baik. Sehingga permasalahan terkait sampah dapat tertanggulangi sedikit demi sedikit dan dapat menaikkan derajat kesehatan masyarakat RW XI Kelurahan Sidotopo hingga masyarakat sekitarnya. Laskar sapu jagat yang terdiri dari anggota karang taruna RW XI dan berusia masih remaja, diharapkan dapat memberi semangat perubahan pada lingkungan agar lebih tanggap terhadap masalah kesehatan, terutama kesehatan lingkungan di wilayah RW XI.

\section{Evaluation}

Setelah serangkaian Program Sapu Jagat selesai dilaksanakan, maka dilaksanakan proses evaluasi yang mana ada beberapa serangkaian kegiatan yang berhasil tercapai dan belum tercapai. Hasil yang belum tercapai yakni pada kegiatan pembentukan Laskar Sapu Jagat. Belum tercapainya kegiatan dikarenakan adanya hasil pre test dan post test yang dilakukan pada anggota karang taruna yang masih belum mencapai kriteria.Hanya $60 \%$ peserta dapat menjawab soal post test dengan benar, sedangkan kriteria yang ditargetkan adalah $>80 \%$ peserta dapat menjawab dengan benar. Untuk kegiatan lainnya sudah berhasil tercapai, seperti pada evaluasi terkait penyuluhan yang dilakukan pada kader dan mereka juga bersedia untuk menjadi agent of change di tengah- tengah masyarakat untuk dapat mengubah perilaku tidak membuang sampah sembarangan.

Pelaksanaan program sapu jagat juga tidak terhindar dari hambatan di lapangan. Salah satunya seperti kegiatan yang dilaksanakan tersebut bersamaan dengan libur natal dan tahun baru, sehingga menyebabkan susahnya mencari data primer menggunakan kuesioner. Lokasi tempat pengumpulan masa seperti balai RW XI yang digunakan bersamaan dengan aktivitas TK dan PAUD dari pagi hingga sore, menyebabkan kesusahan untuk mengumpulkan masa di waktu yang tepat. Selain itu, terdapat beberapa ketua RT yang tidak aktif dan kurang berpartisipasi dalam beberapa program dan masyarakat yang kurang antusias serta kurang memahami program yang dijalankan.

\section{KESIMPULAN}

Program Sapu Jagat merupakan salah satu alternatif program pemberdayaan pada masyarakat sebagai saran untuk menyelesaikan masalah kesehatan pada lingkungan di RW XI Kelurahan Sidotopo Kecamatan Semampir Kota Surabaya. Untuk menghasilkan masyarakat yang mampu untuk mengatasi permasalahan kesehatan maka, dibentuk serangkaian kegiatan didalamnya serta dibentuknya Laskar Sapu Jagat yang nantinya akan bertanggung jawab untuk memberi sanksi kepada masyarakat yang masih kedapatan untuk membuang sampah sembarangan di sungai. Selain itu, para laskar juga diharapkan untuk dapat meneruskan materi-materi yang telah diberikan kepada masyarakat. Sehingga dengan adanya Laskar Sapu Jagat di wilayah RW XI Kelurahan Sidotopo dapat menjadi agent of change terhadap lingkungan disekitar, serta naiknya derajat kesehatan pada masyarakat. Begitupula dengan kader yang telah diberi edukasi untuk pengelolaan sampah dengan cara membuat pupuk kompos Takakura. Diharapkan para kader dapat memperluaskan edukasi tersebut pada masyarakat RW XI Kelurahan Sidotopo, sehingga masyarakat tidak hanya tersadar untuk tidak buang sampah sembarangan namun juga dapat melakukan pengolahan sampah dengan baik. 


\section{ACKNOWLEDGEMENT}

Peneliti mengucapkan terima kasih dengan tulus kepada masyarakat RW XI Kelurahan Sidotopo Kecamatan Semampir Kota Surabaya yang telah mengizinkan untuk melaksanakan penelitian ini disana dan dengan secara sukarela ikut serta dalam penelitian ini sehingga penelitian ini dapat berjalan dengan lancer.

\section{REFERENSI}

Andayani, A. A. I., Martono, E. and Muhamad, M. (2017) 'Pemberdayaan Masyarakat Melalui Pengembangan Desa Wisata Dan Implikasinya Terhadap Ketahanan Sosial Budaya Wilayah (Studi Di Desa Wisata Penglipuran Bali)', Jurnal Ketahanan Nasional, 23(1), p. 1. doi: $10.22146 / \mathrm{jkn} .18006$.

Ariyanti, N. S. et al. (2020) 'Strategy to Determine the Priority of Teachers' Quality Problem Using USG (Urgency, Seriousness, Growth) Matrix’, International Research-Based Education Journal, 2(2), p. 54. doi: 10.17977/um043v2i2p54-62.

Badan Pusat Statistik (2019) 'Kecamatan Semampir Dalam Angka 2019', p. 73.

Dahlan, U. A., Kapas, J. and Yogyakarta, S. (2018) 'KUALITAS LINGKUNGAN SOSRODIPURAN pembuangan / drainase yang di beberapa titik nampak tergenang . Kondisi lingungan seperti meningkatkan keberdayaan suatu komunitas agar mampu berbuat sesuai dengan harkat dan', 2(3), pp. 535-542.

Elamin, M. Z. et al. (2018) 'Analysis of Waste Management in The Village of Disanah, District of Sreseh Sampang, Madura', Jurnal Kesehatan Lingkungan, 10(4), p. $368 . \quad$ doi: 10.20473/jkl.v10i4.2018.368-375.

Febriandi, S. (2020) 'Analisis Faktor Predisposing, Reinforcing, dan Enabling terhadap Perilaku Masyarakat dalam Pemanfaatan Tempat Sampah di Kota Kendari'.

Green, L. W. and Kreuter, M. W. (1999) 'Health Promotion and Planning: An Educational and Enviornmental Approach', Mountain View. doi: 10.1007/s13280-010-0034-3.

Indartik et al. (2018) 'Penanganan Sampah Rumah Tangga Di Kota Bandung ':, Jurnal TeknikLingkungan, 15(3), pp. 195-211.

Kementrian Lingkungan hidup dan Kehutanan (2017) 'Pemantauan Sampah Laut Indonesia Tahun 2017 ', pp. 1-46.

Margolang, N. (2018) 'Pemberdayaan Masyarakat', Dedikasi: Journal of Community Engagment, I(2),pp. 87-99. doi: 10.31227/osf.io/weu8z.

Mawaddah, F. R. (2019) 'Kerjasama Indonesia dan Australia dalam Peningkatan Kualitas KesehatanIbu dan Bayi Baru Lahir di Nusa Tenggara Timur Melalui Program AIPMNH’, (1969), pp. 9-26.

Maya, S., Haryono, S. and Kholisya, U. (2018) 'Pemberdayaan Masyarakat Melalui Pengelolaan Sampah Menjadi Nilai Ekonomis dan Pembentukan Bank Sampah di Kelurahan Tanjung Barat', Proceeding of Community Development, 1(2), p. 157. doi: 10.30874/comdev.2017.21.

Mulasari, S. A. (2013) 'Hubungan Tingkat Pengetahuan Dan Sikap Terhadap Perilaku Masyarakat Dalam Mengolah Sampah Di Dusun Padukuhan Desa Sidokarto Kecamatan Godean Kabupaten Sleman Yogyakarta', Jurnal Kesehatan Masyarakat (Journal of Public Health), 6(3). doi: 10.12928/kesmas.v6i3.1055.

Peraturan Menteri Kesehatan No.65 (2013) 'Pedoman Pelaksanaan dan Pembinaan Pemberdayaan Masyarakat Bidang Kesehatan'.

Purwaningrum, P. (2016) 'Upaya Mengurangi Timbulan Sampah Plastik Di Lingkungan', Indonesian Journal of Urban and Environmental Technology, 8(2), p. 141. doi: 10.25105/urbanenvirotech.v8i2.1421.

Sahil, J. et al. (2016) 'Waste management at Dufa Dufa subdistrict, City of Ternate (in Bahasa Indonesia)', BIOeduKASI, 4(2), pp. 478-487.

Sulaeman, E. S., Murti, B. and Kunci, K. (2015) 'Aplikasi Model Precede-Proceed pada Perencanaan Program Pemberdayaan Masyarakat Bidang Kesehatan Berbasis Penilaian Kebutuhan Kesehatan Masyarakat', 23(3), pp. 149-164.

Tentama, F. (2017) 'Pemberdayaan Masyarakat Dalam Pengelolaan Sampah Rumah Tangga', (October), pp. 135-141. doi: 10.31227/osf.io/m36uz.

Wibisono, A. F. and Dewi, P. (2014) 'Sosialisasi Bahaya Membuang Sampah Sembarangan dan Menentukan Lokasi TPA di Dusun Deles Desa Jagonayan Kecamatan Ngablak', Jurnal Inovasi dan Kewirausahaan, 3(1), p. 25.

Widiyanto, A. F., Yuniarno, S. and Kuswanto, K. (2015) 'Polusi Air Tanah Akibat Limbah Industri Dan Limbah Rumah Tangga', Jurnal Kesehatan Masyarakat, 10(2), p. 246. doi: 10.15294/kemas.v10i2.3388. 